\title{
Resistance to amitraz in the parasitic honey bee mite Varroa destructor is associated with mutations in the $\beta$-adrenergic-like octopamine receptor
}

Carmen Sara Hernández-Rodríguez ${ }^{1}$, Sara Moreno-Martí1., Gabrielle Almecija ${ }^{2,3}$, Krisztina Christmon ${ }^{4}$, Josephine D. Johnson ${ }^{5}$, Marie Ventelon ${ }^{6}$, Dennis vanEngelsdorp ${ }^{4}$, Steven C. Cook ${ }^{5}$, Joel González-Cabrera ${ }^{1 *}$.

${ }^{1}$ Instituto de Biotecnología y Biomedicina BIOTECMED. Department of Genetics, Universitat de València. Dr. Moliner 50. 46100 Burjassot, Spain.

${ }^{2}$ APINOV, Scientific Beekeeping and training Center, 10 rue Henri Bessemer, 17140 Lagord, France.

${ }^{3}$ Institut de Recherche sur la Biologie de l'Insecte, UMR 7621, CNRS-Université de Tours, 37200 Tours, France.

${ }^{4}$ Department of Entomology, University of Maryland, College Park, Maryland 20742, USA.

${ }^{5}$ USDA-ARS Bee Research Laboratory, 13300 Baltimore Ave., Bldg. 306 BARC-E, Beltsville, MD, USA 20705.

${ }^{6}$ Association for the Development of Beekeeping in Auvergne Rhônes Alpes (ADA AURA), 9 allée de Fermat, 63170 Aubière, France

*Corresponding authors:

Email: joel.gonzalez@uv.es, sara.hernandez@uv.es

Instituto de Biotecnología y Biomedicina BIOTECMED. Department of Genetics, Universitat de València. Dr. Moliner 50. 46100 Burjassot, Spain.

Tel: +34963543122

\section{ORCID:}

González-Cabrera, J: 0000-0002-8338-370X

Hernández-Rodríguez, CS: 0000-0002-1234-1190

Almecija, G: 0000-0002-5850-0767

KEYWORDS: Varroa mite, acaricides, target-site resistance, pollinators, honey bee

SHORT RUNNING TITLE: Resistance to amitraz in Varroa destructor 
DECLARATIONS

\section{$34 \quad$ Funding}

35 Joel González-Cabrera was supported by the Spanish Ministry of Economy and

36 Competitiveness, Ramón y Cajal Program (RYC-2013-261 13834). The work at the Universitat

37 de València was funded by the Spanish Ministry of Economy and Competitiveness (grant:

38 CGL2015-65025-R, MINECO/FEDER, UE), Spanish Ministry of Science, Innovation and

39 Universities (grant: RTI2018-095120-B-100/FEDER, UE) and the Foundation for Food and

40 Agricultural Research, Washington DC, USA (grant: 552951). Sample collection in the USA

41 were funded by the US National Honey Bee Disease Survey USDA-APHIS (16-8100-1624-CA,

$42 \quad 15-8100-1624-\mathrm{CA})$.

\section{Declaration of interest}

44 There are no competing interests to declare.

\section{$45 \quad$ Ethics approval}

46 This study does not contain any experiments using any animal species that require ethical

47 approval.

\section{Consent to participate}

$49 \quad$ Not applicable

\section{Consent for publication}

51 All authors consent to the publication of this manuscript.

\section{Availability of data and material}

53 The datasets generated and analysed during the current study are available within the article and

54 its supplementary materials, as well as from the corresponding author on reasonable request.

\section{Authors' contributions}


56 CSHR and JGC designed research. CSHR, SMM, GA, KC, JDJ, JGC conducted experiments

57 and analysed data. GA, MV, KC, SCC, DvE, contributed biological samples. All contribute to

58 writing the manuscript.

\section{Acknowledgements}

60 The authors thank the Bee Informed Partnership (thanks Dr. Nathalie Steinhauer, and Project

61 Apis m), beekeepers and beekeepers' associations from different countries for providing the

62 mite samples used in this study. Thanks to Klemens Krieger for his support and personal

63 implication at the beginning of this research effort. A previous version of this manuscript was

64 revised by Frank Rinkevich (USDA, Baton Rouge, Louisiana) his comments and suggestions

65 were used to improve the final version.

66 


\section{Abstract}

68 Varroa destructor is considered a major reason for high loss rate of Western honey bee (Apis

69 mellifera) colonies. To prevent colony losses caused by $V$. destructor it is necessary to actively

70 manage the mite population. Beekeepers, particularly commercial beekeepers, have few

71 alternative treatments other than synthetic acaricides to control the parasite, resulting in

72 intensive treatment regimens that led to the evolution of resistance in mite populations.

73 To investigate the mechanism of the resistance to amitraz detected in $V$. destructor mites from

74 French and U.S. apiaries, we identified and characterized octopamine and tyramine receptors

75 (the known targets of amitraz) in this species. The comparison of sequences obtained from mites

76 collected from different apiaries with different treatment regimens, showed that the amino acid

77 substitutions $\mathrm{N} 87 \mathrm{~S}$ or $\mathrm{Y} 215 \mathrm{H}$ in the Oct $\beta \mathrm{R}$ were associated with treatment failures reported in

78 French or U.S. apiaries, respectively. Based on our findings, we have developed and tested two

79 high throughput diagnostic assays based on $\operatorname{TaqMan}^{\circledR}$ able to accurately detect mites carrying

80 the mutations in this receptor. This valuable information may be of help for beekeepers when

81 selecting the most suitable acaricide to manage $V$. destructor. 


\section{INTRODUCTION}

84 The ectoparasitic mite Varroa destructor (Anderson and Trueman), shifted hosts from the

85 Eastern honeybee (Apis cerana L.) to the Western honey bee (Apis mellifera L.) in the late

86 1950's (Traynor et al. 2020). Since then, it has spread almost exclusively as clonal lineages

87 throughout the world (Solignac et al. 2005). In A. cerana, V. destructor causes little damage to

88 the colonies since the parasite's population growth is limited as mites can only reproduces in

89 drone brood, which are only available in large numbers early in summer. In contrast, $V$.

90 destructor successfully reproduces in both drone and worker brood of A. mellifera (Beaurepaire

91 et al. 2015). Varroa destructor damages the host by feeding directly on the fat bodies, by

92 vectoring viruses (Boecking and Genersch 2008; Ramsey et al. 2019) and reducing natural

93 defences (Aronstein et al. 2012). If left unmanaged, V. destructor will kill the colonies within a

94 few years (Martin et al. 1998). This mite is considered one of the major causes for seasonal

95 colony losses of the Western honey bee (Steinhauer et al. 2018).

96 Beekeepers have an assortment of chemical and non-chemical methods to implement

97 Integrated Pest Management (IPM) strategies for controlling V. destructor. Most of beekeepers

98 use synthetic chemicals to treat their colonies, since they are easier to use and appear to be most

99 effective and consistent at reducing losses (Rosenkranz et al. 2010; Haber et al. 2019). Globally,

100 the most commonly registered acaricides are the pyrethroids flumethrin and tau-fluvalinate, the

101 organophosphate coumaphos, and the formamidine amitraz. In the past, tau-fluvalinate and

102 coumaphos have been the most widely used treatments, but now these pesticides are less

103 effective. The intensive use of pyrethroids to control $V$. destructor since the 1980's resulted in

104 the independent emergence of resistance to these chemicals in mite populations from Europe

105 and North America (Milani 1995; Elzen et al. 1998; Mozes-Koch et al. 2000; Sammataro et al.

106 2005; Gracia-Salinas et al. 2006; Kim et al. 2009; González-Cabrera et al. 2013; Hubert et al.

107 2014; González-Cabrera et al. 2016; González-Cabrera et al. 2018). Coumaphos was brought to

108 market as an alternative varroacide treatment, but overuse of this product also resulted in the

109 evolution of resistance (Elzen and Westervelt 2002; Maggi et al. 2009; Maggi et al. 2011). 
110 Moreover, residues of varroacides persist and accumulate in beeswax (Bonzini et al. 2011;

111 Calatayud-Vernich et al. 2018; Traynor et al. 2020), posing a sublethal threat to honey bees

112 (Desneux et al. 2007) and possibly maintaining the selection pressure on mite populations, so

113 preventing resistance reversion, as already reported for pyrethroids resistance in $V$. destructor

114 (Milani and Della Vedova 2002; Medici et al. 2016; González-Cabrera et al. 2018; Mitton et al.

115 2018).

To delay the evolution of resistance, rotation of products with different modes of action

is recommended (IRAC; https://www.irac-online.org/), but the lack of effective alternatives makes chemical rotation a non-practical solution for beekeepers. As a result, beekeepers are over reliant on amitraz to control mites (Haber et al. 2019), which would select for resistant mites and it may explain consistent field reports of reduced miticidal (Elzen et al. 1999; Elzen et al. 2000; Rodríguez-Dehaibes et al. 2005; Maggi et al. 2010; Kamler et al. 2016; Rinkevich 2020).

In $V$. destructor, the mechanism of resistance to pyrethroids is already known. It is caused by substitution of key residues within the voltage gated sodium channel (VGSC), the major target site for pyrethroids (González-Cabrera et al. 2013; Hubert et al. 2014; GonzálezCabrera et al. 2016; González-Cabrera et al. 2018). Regarding the resistance to coumaphos, studies carried out with other species have reported that it may be associated with either mutations in its target site, the enzyme acetylcholinesterase, duplication of the acetylcholinesterase gene, or with alterations in the expression of detoxification enzymes (Feyereisen et al. 2015). However, in $V$. destructor, the mechanism(s) involved in the resistance to coumaphos remains unclear. The downregulation of a cytochrome P450 involved in the activation of coumaphos have been described as associated with the resistance reported in mites collected from the Greek island of Andros (Vlogiannitis et al. 2021).

In insects and acari, amitraz binds to the receptors of octopamine and tyramine (Kumar 135 2019). The octopamine (OAR) and the tyramine (TAR) receptors belong to the superfamily of 136 G-protein coupled receptors (GPCRs). GPCRs are known to be involved in recognizing 
137 extracellular messengers, transducing signals to the cytosol, and mediating the cellular

138 responses necessary for the normal physiological functions of organisms (Liu et al. 2021).

139 Octopamine and tyramine receptors are classified as $\alpha$-adrenergic-like octopamine receptors

$140\left(\operatorname{Oct}_{1}\right.$ Rs and $\left.\operatorname{Oct} \alpha_{2} R s\right), \quad \beta$-adrenergic-like octopamine receptors $\left(\operatorname{Oct} \beta_{1} \operatorname{Rs}\right.$, Oct $\beta_{2}$ Rs, and

$141 \mathrm{Oct} \beta_{3} \mathrm{Rs}$ ), and tyramine receptors (TAR1, TAR2, TAR3) (Finetti et al. 2021).

142 Uncovering the molecular mechanisms involved in resistance to pesticides is essential

143 for rapid detection and for designing effective management approaches. In this study, we

144 identified and characterized octopamine and tyramine receptors of $V$. destructor. Two amino

145 acid substitutions in $\operatorname{Oct} \beta_{2} R$ associated with reported field treatment failures of amitraz in

146 France and the U.S. were identified. Finally, two robust high throughput diagnostic assays were

147 developed to identify $V$. destructor mites carrying these mutations in order to aid in resistance

148 management in affected communities.

MATERIAL AND METHODS

151

\section{V. destructor samples}

Samples reporting failures after treatment with amitraz in France were collected in 2019 from

five apiaries belonging to departments 38 (Isère), 42 (Loire), and 63 (Puy-de-Dôme). These apiaries have been treated with amitraz for several years in a row. Mites were collected from capped brood at the end of treatment with amitraz (70 days after the application of strips) and stored at $-20{ }^{\circ} \mathrm{C}$ until used for molecular analysis. Mites collected at departments 4 (Alpes-deHaute-Provence), 26 (Drôme), and 49 (Maine-et-Loire) were not treated with amitraz for at least one year before collection.

U.S. samples were collected as part of different surveys and research efforts not specifically designed for identification of the mechanism of resistance to amitraz (Table S1). Bee Informed

162 Partnership Inc. (BIP) conducted a field trial in the fall of 2018 to test the efficacy of the 
163 product Apivar $^{\circledR}$ (a.i. amitraz) to reduce V. destructor mite infestation in colonies from active

164 commercial beekeeping operations in the U.S. The trial was conducted within 2 commercial

165 beekeeping operations from 2 different geographic regions. A total of 72 colonies (12 colonies

166 per yard, in 3 yards for each operation) were followed over 42 days after treatment. In each

167 yard, half of the colonies were treated with Apivar ${ }^{\circledR}$ while the other half received a positive

168 control product, Apilife $\operatorname{Var}^{\circledR}$ (a.i. thymol). Varroa destructor load was estimated by a lab wash

169 of a sample of $\sim 300$ bees collected from a brood frame (Dietemann et al. 2013).

170 Phoretic mites from the BIP project were collected from colonies taking part in field trials

171 conducted in Oregon and Michigan in 2018. The mites collected were those still in the colony

172 while treatments were ongoing, and so survived at least a partial treatment exposure. Of mites

173 from the 72-colony trial, we randomly chose mites from four colonies being treated with

174 Apivar $^{\circledR}$ and four colonies treated with Apilife $\operatorname{Var}^{\circledR}$ as positive control. We also analysed some

175 mites collected in 2020 as part of the U.S. National Honey Bee Disease Survey (NHBDS). We

176 looked at samples collected from Delaware, Massachusetts, Montana and Pennsylvania. Mite

177 samples previously used to detect tau-fluvalinate resistance in U.S. mite populations and

178 collected from these same states but from 2016 and 2017 NHBDS efforts, were also used

179 (Millán-Leiva et al. 2021a). Samples from New Jersey were sent by a New Jersey state apiarist

180 and were collected from apiaries reporting amitraz failure in 2018 (Styles, Personal

181 communication).

182 Susceptible samples were collected from 2016 to 2019 in apiaries without exposure to amitraz

183 from Iran, New Zealand, Spain, and the UK.

\section{Evaluation of amitraz efficacy}

185 Acaricide efficacy of the amitraz treatments in MM16 and J11 French apiaries were calculated according to the Guideline on veterinary medicinal products controlling Varroa destructor

187 parasitosis in bees (EMA 2010). Amitraz strips were introduced into hives at day 1 and they were removed at day 70. The number of mites in the inspection boards was registered every two 
189 days along the treatment. The residual number of mites was determined with a follow-up

190 treatment using oxalic acid at day 91 and the final count of the dead mites at day 106 . The

191 treatment efficacy (E) was calculated as \% of mite reduction as follows:

$E(\%)=\frac{\text { mites dropped by treatment }(\text { day } 91)}{\text { mites dropped by treatment }+ \text { mites dropped after followup treatment }} \times 100$

192 Identification of receptors and phylogenetic analysis

193 Analysis of the contigs resulting from a transcriptomic analysis of $V$. destructor were previously

194 carried out by our laboratory (BioProject ID PRJNA531374), allowing us to annotate putative

195 octopamine-like receptors. The identity of these sequences was validated after searching in the

196 V. destructor genome (BioProject PRJNA413423) (Techer et al. 2019) via BLASTn. Further

197 comparison with previously annotated octopamine and tyramine receptors from related

198 arthropod species was also carried out via multiple sequence alignment (47 sequences of

199 octopamine and tyramine receptors were used, see Table S2). Protein alignments, tree

200 generation for the phylogenetic analysis, electropherogram editions and sequence assembling

201 were conducted using Geneious software (Geneious version 9.1.5 (http://www.geneious.com

202 (Kearse et al. 2012)). Figures representing protein alignments were generated using CLC

203 Sequencer Viewer 6.8.1. (www.clcbio.com).

204 Amplification and sequencing of receptor cDNAs

205 Pools of 5 mites were ground to powder in liquid nitrogen and total RNA was extracted using 206 the RNeasy Mini Kit (Qiagen) according to the manufacturer's recommendations. RNA (0.5 - 1

$207 \mu \mathrm{g}$ ) was reverse transcribed to cDNA using Maxima H minus First Strand cDNA synthesis kit

208 (ThermoFisher Scientific) using oligo $\mathrm{dT}_{18}(250 \mathrm{ng})$. First strand cDNA was used as a template

209 for PCR. Amplification of $V d_{-} \_c t \alpha_{2} r$ Open Reading Frame (ORF) was conducted using primers

210 Vd_OctAR_5UTR and Vd_OctAR_3UTR. Amplification of $V d \_o c t \beta_{2} r$ ORF was done using

211 primers Vd_OctBR_5UTR1 and Vd_OctBR_3UTR. Amplification of Vd_tar1 ORF was carried

212 out using primers Vd_TAR1_5F and TAR1_3R (Table S3). For PCR amplifying the ORFs, $1 \mu 1$ 
213 of cDNA was mixed with 100 ng of each primer, $25 \mu 1$ of DreamTaq Green PCR Master Mix

214 (ThermoFisher Scientific) and water to a final volume of $50 \mu$ l. Cycling conditions were: $94^{\circ} \mathrm{C}$

215 for $2 \mathrm{~min}$ followed by 35 cycles of $94^{\circ} \mathrm{C}$ for $45 \mathrm{~s}, 60^{\circ} \mathrm{C}$ for $45 \mathrm{~s}$ and $72{ }^{\circ} \mathrm{C}$ for $2 \mathrm{~min}$, and final

216 extension at $72{ }^{\circ} \mathrm{C}$ for $5 \mathrm{~min}$. The PCR fragments were purified using the NucleoSpin ${ }^{\mathrm{TM}} \mathrm{Gel}$ and

217 PCR Clean-up Kit (Thermo Scientific) and sequenced (Stabvida, Portugal) using the sets of

218 primers showed in Table S3.

\section{Genomic DNA sequencing}

220 DNA was extracted from individual mites using DNAzol ${ }^{\circledR}$ reagent (ThermoFisher Scientific)

221 following the manufacturer's protocol. Primers used to PCR amplify and sequence the

222 octopamine and tyramine receptor genes are described in Table S3. The mutation at position

223260 of oct $\beta_{2} r$ was screened by amplifying the genomic region flanking the mutation site with

224 primers Vd_OctBR_5UTR3 and Vd_OctBR_563R. The flanking region of the mutation at

225 position 643 of oct $\beta_{2} r$ was amplified with primers Vd_OctBR_476F and Vd_OctBR_437iR.

226 The PCR conditions were similar to those described above except for the extension step, which

227 was run at $72{ }^{\circ} \mathrm{C}$ for $1 \mathrm{~min}$. PCR amplicons were purified and sequenced as described above.

\section{Protein structure simulation}

229 The online server for protein structure prediction I-TASSER (Yang and Zhang 2015) was used

230 to generate a theoretical three-dimensional structure of $V$. destructor $\operatorname{Oct}_{2} \mathrm{R}$ and TAR1. From

231 the default settings of I-TASSER, the structure conformation with higher C-score for each

232 receptor was chosen. C-score is typically in the range of $[-5,2]$, where a C-score of a higher

233 value indicates a model with a higher confidence and vice-versa. The topology of the $\operatorname{Oct} \beta_{2} R$

234 receptor in the membrane was represented using the webservice PROTTER (Omasits et al.

235 2014), which uses Phobius (Kall et al. 2004) for prediction of transmembrane topology and the

236 N-terminal location. The predictions about the effects of the mutations in the receptor were

237 obtained with SNAP2 (Hecht et al. 2015), PolyPhen2 (Adzhubei et al. 2010), I-Mutant2.0

238 (https://folding.biofold.org/i-mutant/i-mutant2.0.html), and HOPE (Venselaar et al. 2010). 


\section{$239 \operatorname{TaqMan}^{\circledR}$ diagnostic assays}

240 The sequence of the $V d \_o c t \beta_{2} r$ gene described in this study was used to design primers

241 (flanking the $\mathrm{N} 87$ and Y215 positions in the Vd_Oct $\beta_{2} \mathrm{R}$ protein) and two minor groove-binding

242 probes (MGB) (ThermoFisher Scientific) using the Custom TaqMan ${ }^{\circledR}$ Assay Design Tool

243 (https://www.thermofisher.com/order/custom-genomic-products/tools/genotyping/). For the

244 detection of N87S mutation, forward OctR_Vd_87_F (5'-CGCCCTGTTCGCGATGA-3') and

245 reverse OctR_Vd_87_R (5'-ATCCACTTGCCCGAAATGGT-3') primers (standard

246 oligonucleotides with no modification) were used. The probe Vd_N87S_V (5'-

247 ACGACGCATTGAATG-3') was labelled with the fluorescent dye VIC $^{\circledR}$ for the detection of

248 the wild-type allele, and the probe Vd_N87S_M (5'-CGACGCACTGAATG-3') was labelled

249 with the fluorescent dye $6 \mathrm{FAM}^{\mathrm{TM}}$ for detection of the N87S mutation. For the detection of

250 Y215H mutation, forward OctR_Vd_215_F (5'-GGATACCGTGCTCAGTAATGCT-3') and

251 reverse OctR_Vd_215_R (5'-CTGTCGGGTCGCTTCTAGATAG-3') primers (standard

252 oligonucleotides with no modification) were used. The probe Vd_Y215H_V (5'-

253 ATGCGCCAATAAGTGAAT-3') was labelled with the fluorescent dye VIC $^{\circledR}$ for the detection

254 of the wild-type allele, and the probe Vd_Y215H_M (5'-CGCCAATGAGTGAAT-3') was

255 labelled with the fluorescent dye $6 \mathrm{FAM}{ }^{\mathrm{TM}}$ for detection of the $\mathrm{Y} 215 \mathrm{H}$ mutation. Each probe

256 also had a 3'non-fluorescent quencher and a minor groove binder at the 3' end. This minor

257 groove binder increases the Tm between matched and mismatched probes providing more

258 accurate allele discrimination (Afonina et al. 1997). Genomic DNA extraction from adult mites

259 and TaqMan ${ }^{\circledR}$ assays were carried out as described by González-Cabrera et al. (2013) using a

260 StepOne Real-Time PCR System (ThermoFisher Scientific).

RESULTS 
264 Manual curation of transcriptomic data obtained in our laboratory (BioProject ID

265 PRJNA531374) showed that a few contigs contained sequences likely belonging to G protein-

266 coupled receptors (GPCR) and more specifically to octopamine-like receptors. These were used

267 as queries to search via BLASTn in the recently released $V$. destructor genome (Techer et al.

268 2019). Thus, contigs c139848_g8_i1 (1227 bp), and c143491_g6_i5 (2547 bp), mapped to the

269 locus LOC111253729, annotated as a G-protein couple receptor (XP_022669321.1), and to the

270 locus LOC111251882, annotated as an octopamine receptor beta-2R-like (XP_022664702.1),

271 respectively. Since in Rhipicephalus microplus, a tyramine receptor (GenBank accession

272 number CAA09335) was previously associated with resistance to amitraz (Kumar 2019), the

273 homologous gene was searched in the V. destructor's genome. The locus LOC111254088,

274 annotated as octopamine-like receptor in the V. destructor database, showed the highest identity

275 with the gene encoding the CAA09335 protein from $R$. microplus. Phylogenetic analysis was

276 then conducted with these proteins and with others, annotated as octopamine receptors, from

277 several arthropod species (Table S2). The phylogenetic tree obtained from the alignment of 47

278 proteins clustered into three main groups, consisting of $\alpha_{2}$-adrenergic-like octopamine receptors

$279\left(\mathrm{Oct} \alpha_{2} \mathrm{Rs}\right), \beta$-adrenergic-like octopamine receptors (Oct $\left.\beta \mathrm{Rs}\right)$, and type 1 Tyramine receptors

280 (TAR1). The branch corresponding to Oct $\beta$ Rs included three classes of receptors: Oct $\beta_{1} R$,

$281 \operatorname{Oct} \beta_{2} R$, and $\operatorname{Oct} \beta_{3} R$. Regarding the proteins from $V$. destructor in the alignment,

282 XP_022669321 grouped with Oct $\alpha_{2}$ Rs; XP_022664702 is included in the branch corresponding

283 the Oct $\beta_{2}$ Rs, and XP_022670329 is related with TAR1s (Fig. 1). From this analysis, we called

284 XP_022669321, XP_022664702, and XP_022670329 proteins, as Vd_Oct $\alpha_{2} R, V d \_O c t \beta{ }_{2} R$, and

285 Vd_TAR1, respectively.

286 Vd_Oct $\alpha_{2} R$ protein

287 Vd_Oct $\alpha_{2} R$ encoded for a 532 amino acids protein. When Vd_Oct $\alpha_{2} R$ was aligned to other $\alpha$ -

288 adrenergic-like octopamine receptors, a high degree of conservation was observed among

289 species, mainly in the regions corresponding to the predicted seven $\alpha$-helices of the proteins' 
290 tertiary structure (Fig. 2A). The percentage of identity between Vd_Oct $\alpha_{2} R$ and the $\alpha$-receptors

291 from other acari species was $82 \%$ for Galendromus occidentalis, $68 \%$ for Tropilaelaps

292 mercedesae, $52 \%$ for $R$. microplus and $50 \%$ for Ixodes scapularis. Conserved motifs common

293 to GPCR were found in $\alpha$-helices III, VI, VII, and the C-terminus (Fig. 2A).

\section{Vd_Oct $\beta_{2} \mathbf{R}$ protein}

295 Vd_Oct $\beta_{2} R$ encoded for a 439 amino acids protein. The percentage of identity between

296 Vd_Oct $\beta_{2} R$ and the $\beta$-adrenergic-like octopamine receptor from other closely related acari

297 species in the cladogram were $83 \%$ for T. mercedesae, $79 \%$ for G. occidentalis, $68 \%$ for $R$.

298 microplus and $65 \%$ for I. scapularis. Multiple sequence alignment of Oct $\beta$ Rs from these

299 species showed that, as in $V d \_O c t \alpha_{2} R, V d \_O c t \beta_{2} R$ contained highly conserved regions 300 corresponding to the seven $\alpha$-helices typical of GPCR (Fig. 2B). The modelling of the 301 Vd_Oct $\beta_{2} R$ three-dimensional structure, obtained with I-TASSER online server, showed the 302 common structure described in GPCRs: seven transmembrane (TM) helical bundle connected 303 by three extracellular loops (EL) and three intracellular loops (IL) (Fig. 3A). The N-terminus of 304 the protein was at the extracellular side and the C-terminus was located intracellularly. In this structure, the ligand-pocket would be close to the extracellular region and surrounded by the transmembrane helical domain (Marsh 2015). The molecular simulation of transmembrane regions using Phobius software predicted which residues were "buried" into the membrane or exposed to intracellular or extracellular regions (Fig. 4). Other features characterizing Oct $\beta R$ were also found in $\mathrm{Vd} \_$Oct $\beta_{2} \mathrm{R}$ (Fig. 4). The receptor had two highly conserved cysteine residues in TM3 and EL2 which form a disulphide bond, which is important for stabilizing the conformation of the extracellular region and shaping the entrance to the ligand-binding pocket (Rader et al. 2004). Three motifs of amino acids involved in molecular switches in GPCRs during activation were also found in Vd_Oct $\beta_{2} R$ : i) the D[E]RY motif in helix III, which often forms a so-called "ionic lock". The ionic lock was suggested as a characteristic of the inactive conformation of GPCRs, blocking the G-protein binding at the cytoplasmic region; ii) the 
316 CWxP motif observed in $\alpha$-helix VI, considered as one of the micro-switches that have

317 substantially different conformations in the active state versus the inactive state of the receptor;

318 iii) the NP(L/I)IY motif in helix VII, involved in a permanent rotameric change (Filipek 2019)

319 (Fig. 2B and Fig. 4). As in most of the GPCR structures, the C-terminus contains a 3-4 turn $\alpha$ -

320 helix, $\alpha$-helix VIII, that runs parallel to the membrane and is characterized by a common

$321(\mathrm{~F}[\mathrm{R} / \mathrm{K}] \mathrm{xx}[\mathrm{F} / \mathrm{L}] \mathrm{xxx})$ amphiphilic motif (Zhang et al. 2015). Putative amino acids involved in

322 octopamine binding are extended through a 222 amino acids region between W106 and Y327.

\section{Vd_TAR1 protein}

Vd_TAR1 encoded for a 369 amino acids protein. Vd_TAR1 was aligned to the acari tyramine receptors more similar to the tyramine receptor of $R$. microplus (CAA09335), in which mutations associated with resistance to amitraz have been described (Kumar 2019). As with Vd_Oct $\alpha_{2} R$ and Vd_Oct $\beta_{2} R$, the regions corresponding to the predicted seven helices in the tertiary structure of the proteins are conserved among species (Fig. 2C). The modelling of the three-dimensional structure Vd_TAR1 also showed the described structure for GPCR: seven hydrophobic transmembrane domains and six hydrophilic loops (Fig. 3B). Like in other TAR1 receptors, the third intracellular loop of Vd_TAR1 is longer than that in Oct $\beta_{2}$ Rs. The percentage of identity between Vd_TAR1 and the tyramine receptors from other acari species is $94 \%$ for $T$. mercedesae, $61 \%$ for $R$. microplus and for I. scapularis, and $56 \%$ for $G$. occidentalis.

\section{$V d \_o c t \alpha_{2} r, V d \_o c t \beta_{2} r$ and $V d \_t a r 1$ genes}

The cDNA of $V d \_o c t \alpha_{2} r, V d \_o c t \beta_{2} r$ and $V d \_t a r l$ were obtained by RT-PCR, using as template the same RNA samples used for transcriptomics. Sequencing of the ORFs showed a full identity of these cDNAs with XM_022813586, XM_022808967 and XM_022814594, corresponding to the mRNA of Vd_Oct $\alpha_{2} R, V d \_O c t \beta_{2} R$, and Vd_TAR1, respectively. 
342 Exon 1, Exon 2 and Exon 3. The start codon (position 3,746 at the mRNA) is sited in Exon 4.

343 The stop codon (position 5,344 at the mRNA) and the 3'UTR are in the Exon 9, the largest

344 exon. The length of all the exons and introns of $V d \_o c t \alpha_{2} r$ is shown in Fig. 5A.

345 The lengths of $V d \_o c t \beta_{2} r$ ORF, mRNA, and full gene sequences are 1,101 bp, 11,863 bp, and

$346141,186 \mathrm{bp}$, respectively. The $V d \_o c t \beta_{2} r$ gene comprises two exons and one intron (Fig. 5B).

347 Exon 1 contains the 5'UTR and the start codon (position 4,507 at the mRNA), and Exon 2

348 contains the stop codon (position 5,607 at the mRNA) and the 3'UTR. Between Exon 1 and

349 Exon 2 there is a long intron of 129,323 bp (Fig. 5B).

350 The $V d \_t a r l$ gene has a length of $22,226 \mathrm{bp}$, transcribed into an mRNA of 2,788 bp in which an

351 ORF of $1,110 \mathrm{bp}$ is found. The Vd_tarl gene comprises 4 exons and 3 introns (Fig. 5C). The

352 5'UTR is extended along Exon 1 and Exon 2. The start codon (position 1,162 at the mRNA) is

353 sited in Exon 2. The stop codon (position 2,769 at the mRNA) and the 3'UTR are in the Exon 4.

354 The length of all the exons and introns of Vd_tarl is shown in Fig. 5C.

$V d \_o c t \beta_{2} r$ and $V d \_t a r 1$ sequences in $V$. destructor mites susceptible to amitraz

Total RNA was isolated from pools of five to ten $V$. destructor adult females collected in Iran,

357 New Zealand, Spain and the UK between 2016 and 2019 from colonies without amitraz treatment. As mutations associated with the resistance to amitraz has been described in Oct $\beta R$ and TAR1 receptors, RNA from these susceptible mites was reverse transcribed into cDNA to amplify the full length of $V d \_o c t \beta_{2} r$ and $V d \_t a r l$ ORFs. The sequencing of $V d \_o c t \beta_{2} r$ and $V d \_t a r 1$ ORFs of mites from these countries showed identical sequences to those previously identified as wild-type in this paper (XM_022813586 and XM_022814594, respectively).

We identified a single point mutation in $V d_{-} o c t \beta_{2} r$ gene (substitution of $\mathrm{A}$ to $\mathrm{G}$ at nucleotide 260 of the ORF) in mites extracted alive from the brood, right after finishing the treatment with 
treatment. This mutation results in an asparagine (AAT) to serine (AGT) substitution at position 87 of the Vd_Oct $\beta_{2}$ R protein (N87S) (Fig. 6A). To validate this result, total DNA was isolated from 24 individual mites collected in 3 colonies from the same apiary. The genomic region comprising the mutation was amplified and sequenced. All sequenced mites showed the N87S mutation (Table 1). The same analysis was carried out with mites from the apiaries MAP (Loire department) and MHRA (Isère department), where the treatment with amitraz also failed. The mutation was present in $75 \%$ of the mites from MAP apiary, and in $71 \%$ of the mites from the MHRA apiary (Table 1). In colonies MM16 and J11 (both located in apiaries at Puy-de-Dôme department) the mutation N87S was detected in 77 and $57 \%$ of the mites, respectively (Table 1). Further analysis showed that the efficacy of amitraz treatment was $92 \%$ in colony MM16 and $77 \%$ in $\mathrm{J} 11$. The occurrence of this mutation was also studied in three apiaries from nearby departments in which amitraz was not used the year before sampling. Apiaries VB (Alpes-deHaute-Provence department), AmA (Maine-et-Loire department) and DE (Drôme) were all treated with oxalic acid. None of the mites from VB and AmA carried the mutation N87S while $26 \%$ of the mites from DE were mutants (Table 1). Altogether, these data show circumstantial evidence that there is an association between the mutation $\mathrm{N} 87 \mathrm{~S}$ and amitraz treatment failure.

The ORF of Vd_tarl was also sequenced in pools of mites collected from all French apiaries analysed in this study. None of the analysed mites showed any change in the sequence when compared with the wild-type Vd_tarl.

\section{Y215H mutation}

In the U.S., a state apiary inspector reported the failure of the amitraz treatment in some colonies from New Jersey in 2018 (Styles, Personal communication). The Vd_oct $\beta_{2} r$ and $V d \_t a r l$ gene sequences were examined in mites collected from four of these colonies. No mutations were detected in Vd_tarl gene and the mutation N87S, identified in French samples, was also not detected. However, a new single point mutation was identified in the $V d_{-}$oct $\beta_{2} r$ gene from mites collected from the four colonies. The substitution of $\mathrm{T}$ to $\mathrm{C}$ at position 643 of the ORF results in a tyrosine (TAT) to histidine (CAT) substitution at position 215 of the 
394 Vd_Oct $\beta_{2}$ R protein (Y215H) (Fig. 6B). This mutation was detected in 50 to $96 \%$ of the mites 395 sequenced from these colonies (Fig. 7, Table S1).

396 In order to gather data regarding the presence of the mutation $\mathrm{Y} 215 \mathrm{H}$ in New Jersey from 397 previous years, mites collected in 2016 from different colonies in this state were also sequenced.

398 We did not detect this mutation in any of the colonies analysed (Fig. 7, Table S1).

399 Since the presence of the Y215H mutation seemed related with the reduced susceptibility to 400 amitraz, we analyzed mite samples obtained from a BIP project evaluating the efficacy to 401 Apivar $^{\circledR}$ in Oregon and Michigan in 2018. These trials were suggestive of amitraz treatment 402 failure (Nathalie Steinhauer, personal communication). Samples of phoretic V. destructor mites 403 were collected from bees sampled from colonies while being treated with Apivar ${ }^{\circledR}$. The Y215H 404 mutation was detected in 88 and $96 \%$ of the mites from the two colonies we examined that 405 were treated with Apivar ${ }^{\circledR}$ in Oregon, and in the 94 and $90 \%$ of the mites from the two colonies treated with Apivar ${ }^{\circledR}$ in Michigan (Fig. 7, Table S1). Colonies from the same apiaries but treated 407 with thymol instead of Apivar ${ }^{\circledR}$ were also analyzed. The Y215H mutation was present in 96 and $408100 \%$ of the mites collected in the two colonies from Oregon and the same frequencies were 409 also recorded in the two colonies from Michigan (Table S1). On the other hand, mites collected 410 from these two states before 2018 (Millán-Leiva et al. 2021a) were also sequenced. The 411 mutation was found but at much lower frequency, suggesting that the mutation is a relatively 412 recent event (Fig. 7, Table S1).

413 To estimate when the mutation first evolved in the U.S. population, we compared the 414 presence of $\mathrm{Y} 215 \mathrm{H}$ in samples collected in 2020 with samples collected in previous years in 415 several U.S. states (Millán-Leiva et al. 2021a). Results from Delaware, Massachusetts, Montana 416 and Pennsylvania showed that the mutation was practically non-existent in 2016 but its 417 incidence has increased since (Fig. 7, Table S1).

\section{Diagnostic assay}


419 Two high throughput allelic discrimination assays based on TaqMan ${ }^{\circledR}$ were developed to enable

420 rapid and accurate genotyping of N87S and Y215H mutations in individual mites. For each real-

421 time PCR assay, we designed two fluorescent labelled probes to discriminate between wild-type

422 and mutant alleles. The probes selective for N87 or Y215 wild-type alleles were labelled with

$423 \mathrm{VIC}^{\circledR}$ while the others, selective for $\mathrm{S} 87$ or $\mathrm{H} 215$ alleles, were labelled with $6 \mathrm{FAM}^{\mathrm{TM}}$.

424 Therefore, an increase in $\mathrm{VIC}^{\circledR}$ fluorescence indicates the presence of the wild-type allele, while

425 an increase in $6 \mathrm{FAM}^{\mathrm{TM}}$ fluorescence indicates the presence of the mutant allele. An

426 intermediate increase in the fluorescence of both dyes indicates that the mite is heterozygous for

427 the mutation. Twenty-four mites in which the nucleotide at each of the mutation sites of

$428 V d_{-}$oct $\beta_{2} r$ was known by previous sequencing were genotyped by TaqMan ${ }^{\circledR}$. The results

429 showed a perfect correlation between data from sequencing and genotyping. Genotyped mites

430 were either homozygous for the wild-type allele (N87 or Y215), the mutant allele (S87 or

431 H215), or heterozygous for each mutation (Fig. 8).

\section{DISCUSSION AND CONCLUSION}

434 Here we identified two amino acid substitutions, located in the $\beta$-adrenergic octopamine

435 receptor of $V$. destructor, that seem to be associated with field treatment failures using amitraz

436 in samples collected in France and the U.S. Our data also show circumstantial evidence of an

437 independent evolution of resistance in both locations.

438 Amitraz is a formamidine that has been widely used as an acaricide since its discovery back in

4391972 (Harrison et al. 1972). Nowadays, it is one of the main alternatives for controlling

440 varroosis worldwide. This compound mimics the action of the neurotransmitters octopamine

441 and tyramine and blocks their receptors (Hollingworth and Lund 1982). Therefore, it is likely

442 that modifications in key sites of the octopamine or tyramine receptors would be associated with

443 the treatment failures reported by beekeepers after treatments with amitraz-based acaricides. 
444 A joint analysis of transcriptomic (BioProject ID PRJNA531374) and genomic data (Techer et

445 al. 2019), alongside with data available in public databases, allowed the characterization of

446 proteins from three different classes of receptors in this mite: an $\alpha$-adrenergic-like octopamine

447 receptor $\left(\mathrm{Vd} \_\mathrm{Oct}_{2} \mathrm{R}\right)$, a $\beta$-adrenergic-like octopamine receptor $\left(\mathrm{Vd} \_\mathrm{Oct} \beta_{2} \mathrm{R}\right)$ and a tyramine

448 type 1 receptor (Vd_TAR1). A more in-depth in silico study of the secondary and tertiary

449 structures of these proteins showed that they have structural features typical of the superfamily

450 of G-protein coupled receptors, such as the seven transmembrane domains and the classic

451 distribution of extracellular and intracellular loops (Finetti et al. 2021). Moreover, the

452 occurrence of highly conserved residues and several sequence motifs common to $\alpha$ - and $\beta$ -

453 adrenergic octopamine receptors in Vd_Oct $\alpha \mathrm{R}$ and Vd_Oct $\beta \mathrm{R}$, confirmed the correct

454 identification and classification of these proteins as octopamine receptors in $V$. destructor. It

455 was once thought that amitraz only interacts with octopamine receptors (OAR). However,

456 during that time, tyramine type 1 receptors have been wrongly classified as OAR (Chen et al.

457 2007). Later, this receptor was classified as Oct/TyrR (Baron et al. 2015) and recently, tyramine

458 type 1 receptor was finally classified as TAR (Farooqui 2012; Finetti et al. 2021). However, as

459 this is a recent change in the classification, it is still not updated in public databases, that

460 maintain erroneous annotations, leading to confusion when trying to identify and classify this

461 family of receptors. This is the case of V. destructor, in which Vd_TAR1 (XP_02270329) is

462 described as octopamine receptor-like, actually being a tyramine receptor, as we have

463 thoroughly described in this study.

464 Resistance to amitraz in Varroa have been reported in populations from different locations

465 around the world, such as the U.S. (Elzen et al. 1999; Elzen et al. 2000; Rinkevich 2020),

466 Mexico (Rodríguez-Dehaibes et al. 2005), Argentina (Maggi et al. 2010), the Czech Republic

467 (Kamler et al. 2016) and France (Almecija et al. 2020). In addition to these publications,

468 anecdotal reports of reduced amitraz efficacy are widely discussed among beekeepers

469 (Rinkevich 2020). However, until now, the mechanism causing this lack of efficacy was

470 unknown. 
471 The mechanism of resistance to amitraz has been thoroughly studied in the cattle tick $R$.

472 microplus (Baxter and Barker 1999; Chen et al. 2007; Corley et al. 2013; Baron et al. 2015;

473 Koh-Tan et al. 2016; Jonsson et al. 2018). In this species, the resistance detected in the field has

474 been associated with polymorphisms in the octopamine and tyramine receptors, suggesting that 475 target site insensitivity is the most common mechanism of resistance to amitraz. Chen et al.

476 (2007) found two amino acid substitutions (T8P and L22S) in the tyramine receptor gene that

477 were only present in American strains highly resistant to amitraz. Further analysis by Baron et

478 al. (2015) supported the association of these two SNPs with the resistance in field samples

479 collected in South Africa. However, previous analysis of the same gene with samples collected

480 in Australia did not find any SNPs differentiating susceptible from resistant strains (Baxter and

481 Barker 1999). In an attempt to address this issue, Corley et al. (2013) widen the scope of the

482 analysis to other octopamine receptors using the same amitraz-resistant Ultimo strain analysed

483 by Baxter and Barker. They found an increased frequency of the mutation I61F in the $\beta$ -

484 adrenergic octopamine receptor (RmBAOR) providing circumstantial support for associating

485 this mutation with the resistance to amitraz in the Ultimo strain. Supporting this association, an

486 I45F mutant of Bombyx mori OAR2 (equivalent to I61F in RmBAOR) showed reduced sensitivity to the amitraz metabolite DPMF ( $\mathrm{N}^{2}$-(2,4-Dimethylphenyl)- $\mathrm{N}^{1}$-methyformamidine) in HEK-293 cells (Takata et al. 2020). In a different study, cell lines derived from acaricideresistant $R$. microplus colonies from Colombia contained a $36 \mathrm{bp}$ duplication in the RmBAOR gene leading to a 12 amino acid insertion in the first transmembrane domain of the protein (Koh-Tan et al. 2016). Further analyses of resistant R. microplus from Brazil, Mexico, Australia, Thailand and South Africa supported the association of I61F with the resistance, but also described novel SPNs in the RmBAOR associated with amitraz resistance in specific 494 populations (Jonsson et al. 2018).

To date, there is no reported association between mutations in $\alpha$-adrenergic octopamine receptors and resistance to amitraz. Therefore, we analysed Vd_TAR1 and Vd_Oct $\beta_{2} R$, the receptors of $V$. destructor phylogenetically closer to those of $R$. microplus reporting 
498 polymorphisms associated with amitraz resistance. None of the mutations described in $R$.

499 microplus were found in the $V$. destructor samples analysed in this study. However, we did

500 identify two novel non-synonymous substitutions in the $V d \_$oct $\beta_{2} r$ gene with a differential

501 geographical distribution. A substitution of asparagine 87 to serine (N87S) associated with

502 treatment failures in France, and a substitution of tyrosine 215 to histidine (Y215H) in samples

503 collected across the U.S. from colonies reporting low amitraz efficacy. None of the samples

504 analysed in this study were collected as part of a structured sampling strategy designed to

505 elucidate the mechanism of resistance to amitraz. Rather, most of them were part of projects,

506 experiments or surveys conducted to validate previous reports of treatment failures. After a

507 careful case-by-case analysis of the sampling and treatment history, it is possible to draw

508 conclusions on whether these mutations are associated with the resistance to amitraz. In the case

509 of samples collected in France, when the sampling was conducted after finishing the treatment

510 with amitraz (Table 1), a significant number of mites were mutants for N87S (always above 50

$511 \%$ ), showing an association with the efficacy observed in the field. On the other hand, the

512 samples collected from colonies not exposed to amitraz at least the year before the sample

513 collection were mostly wild-type. This suggests that amitraz is exerting a significant selection

514 pressure, favouring the prevalence of N87S mutants in the populations after an intensive

515 treatment regime for many years. In the U.S., the samples were collected as part of different

516 projects and screening efforts using different sampling approaches. In these cases, whenever the

517 mites (phoretic) were collected after finishing the treatment with amitraz (NJ-M- NJ-M-001,

518 NJ-M-002, NJ-M-008, NJ-EP-2) or when the treatment was still ongoing (OR-AV01, OR-

519 AV02, MI-22, MI-33), the frequency of mutants was very high (Table S1), indicating an

520 association between the presence of the mutation $\mathrm{Y} 215 \mathrm{H}$ and the survival after exposure.

521 However, the samples collected from other colonies (OR-AL38, OR-AL51, MI-56, MI-58),

522 taking part in the same field assay in Oregon and Michigan but treated with thymol, also

523 showed a high frequency of mutant mites. This may be explained considering that amitraz has

524 been used intensively for long time in these locations. Thus, given the high movement of mites

525 within apiaries (Kulhanek et al. 2021), it is possible that a significant part of the population was 
526 already mutant before starting the field trials in 2018. The historical data gathered after the 527 analysis of samples collected in 2016 and 2017 also supports this idea. Our data show that the 528 mutation was nearly absent in the samples collected in several states in 2016, with only one 529 sample with mutants in Michigan (MI-09). Yet, in 2017, although some samples were still 530 completely wild-type, many of them show that the mutation was present in a significant number 531 of mites. Hence, it is reasonable to think that in 2018 , following the same treatment regime with 532 amitraz, the frequency of mutants -e.g. resistant mites- would predominate (Table S1).

533 The joint analysis of the data also suggests that the resistance have evolved independently at 534 both locations. The mutation N87S was detected only in mites collected in France while Y215H 535 was detected only in the mites collected in the U.S. This result is yet another example of the capacity of this species to evolve resistance to the same acaricide via multiple independent 537 pathways. This was already described for the resistance to pyrethroids based-acaricides. In 538 Europe mites carry mostly the mutation L925V in the VGSC, while those from the U.S. carry 539 the mutations L925M and L925I (González-Cabrera et al. 2013; González-Cabrera et al. 2016; 540 González-Cabrera et al. 2018; Millán-Leiva et al. 2021a). A more recent study also evidenced 541 that this was the result of a parallel and independent evolution process (Millán-Leiva et al. 542 2021b). Following the same rationale, the different mutations associated with the resistance of $543 R$. microplus to amitraz that evolved in different locations, in different receptor proteins and also 544 in different residues of the same protein (Chen et al. 2007; Corley et al. 2013; Koh-Tan et al. 545 2016; Jonsson et al. 2018), are a very good example of the many possibilities that can be found 546 in V. destructor. As we have screened a relatively small number of samples, from few locations, 547 a larger screening effort is called for to draw a more accurate and complete picture of the 548 situation.

549 A thorough in silico analysis of the $\beta$-octopamine receptor of Schistocerca gregaria showed that 550 the nonpolar residues of the transmembrane regions are buried in the receptor core to form a 551 hydrophobic pocket (active pocket) that is closed to the extracellular region and surrounded by 552 the transmembrane domain ( $\mathrm{Lu}$ et al. 2017). According to the in silico model, asparagine 87 is 
553 located at the end of helix II of Vd_Oct $\beta_{2} \mathrm{R}$ (Fig. 3), positioned near to the residues predicted as

554 the putative binding site for octopamine. In the N87S mutation, the mutant residue is smaller

555 and more hydrophobic (N -0.78; S -0.18) (Eisenberg et al. 1984) than the wild-type residue and

556 this might lead to loss of hydrogen bonds and/or disturb the correct folding of the protein. Since

557 this mutation is in a domain that is important for the main activity of the receptor, it might

558 somehow disturb its function. A more targeted study found out that in Sitophilus oryzae amitraz

559 and octopamine might not share the same binding site, although the two sites were close to one

560 another (Braza et al. 2019). Docking of amitraz to S. oryzae tyramine receptor showed eight

561 residues of the receptor closely interacting with this ligand. One of these amino acids was

562 Asn91, corresponding to Asn87 in V. destructor. When this position was examined across

563 species, it was found that this residue was totally conserved in both, $\beta$-adrenergic octopamine

564 and tyramine receptors (Fig. S1A). On the other hand, in $\alpha$-adrenergic-like octopamine

565 receptors, this position shows a serine residue instead of an asparagine, indicating a possible

566 different interaction of amitraz with Oct $\alpha$ Rs in comparison with Oct $\beta$ Rs and TAR1s. Indeed,

567 Kita et al. (2017) showed that the potency of amitraz and its metabolite DPMF to activate $B$.

568 mori octopamine receptors was 347- and 2274-fold higher in $\beta$-adrenergic-like octopamine

569 receptors than in $\alpha$-adrenergic $\square$ like octopamine receptors, respectively. Additionally, based on

570 the consensus sequence for N-linked glycosylation (NXT/S), residue N87 is predicted as a

571 putative $\mathrm{N}$-glycosylation site in $\mathrm{Vd}$ _Oct $\beta_{2} \mathrm{R}$. N-glycosylation has been shown to be important

572 for many GPCRs especially in correct folding, surface expression, signalling, and dimerization

573 (Nørskov-Lauritsen and Bräuner-Osborne 2015; Patwardhan et al. 2021). Actually, it has been

574 reported that $\mathrm{N}$-glycosylation of the $\alpha_{1 \mathrm{D}}$-adrenergic receptor is required for correct trafficking

575 and complete translation of a nascent, functional receptor (Janezic et al. 2020), and that the N-

576 glycosylation of the $\beta_{2}$-adrenergic receptor regulates its function by influencing receptor

577 dimerization ( $\mathrm{Li}$ et al. 2017). Therefore, if the asparagine at position 87 of the $\mathrm{Vd} \_\mathrm{Oct} \beta{ }_{2} \mathrm{R}$ is

578 indeed a N-glycosylation site, its substitution for a serine residue may affect the integrity and

579 functionality of this receptor. 
580 The mutation $\mathrm{Y} 215 \mathrm{H}$ is sited in the fifth transmembrane segment of the Vd_Oct $\beta_{2} \mathrm{R}$ (Fig. 4). In

581 this case, the wild-type residue is more hydrophobic than the mutant residue (Y $0.26 ; \mathrm{H}-0.4)$

582 (Eisenberg et al. 1984). After in silico analysis, the prediction results based on secondary

583 structure showed a negative effect of the substitution (score +50 with SNAP2; $100 \%$

584 probability of damage with PolyPhen2). The analysis of the tertiary structure of the mutant

585 protein indicated a decrease of the stability (Reliable index: 8 with I-MUTANT), and predicted

586 that the hydrophobic interactions, either in the core of the protein or on the surface, would be

587 lost (HOPE). Therefore, it seems that the change from tyrosine to histidine in this domain of the

588 protein could seriously alter the conformation of the helix and its surroundings, which can affect

589 the interaction of the receptor with the ligand. This hypothesis is supported by the conservation

590 of the tyrosine residue at this position of the protein among all species analysed in this study.

591 (Fig S1B).

592 Amitraz exerts its acaricidal action as an agonist of octopamine. In invertebrates, octopamine 593 acts as neurotransmitter, neuromodulator, and neurohormone, playing a fundamental role on 594 physiological processes (Farooqui 2007). By binding to G-coupled receptors on the surface of 595 neurons and other cells, octopamine functions as neurotransmitter affecting diverse behaviours 596 such as excitation, aggression and egg laying (Roeder 2005). In ticks, sublethal and behaviour 597 effects of amitraz are considered more important than lethality in the mode of action. It has been 598 shown that amitraz causes hyperactivity, leg waving, detaching behaviour and inhibition of the 599 reproduction (Page 2008). Therefore, the effect of amitraz goes beyond killing like a poison; it 600 is effective by acting as a behaviour disruptor, inhibiting the mites' ability to remain attached to 601 the bees before killing them. This suggests that lab bioassays that only measure $\mathrm{LD}_{50}$ may 602 underestimate resistance as it would express under field conditions. Thus, looking for 603 associations between the presence of mutations and the survival of mites in colonies treated 604 under field conditions, is perhaps a more appropriate approach to elucidate the mechanism of 605 resistance to products that cause behavioural changes that result in death, rather than cause 606 death directly. 
607 Our findings supports the association of the mutations $\mathrm{N} 87 \mathrm{~S}$ and $\mathrm{Y} 215 \mathrm{H}$ in the $\beta$-adrenergic-

608 like octopamine receptor of $V$. destructor with the resistance to amitraz reported in the field.

609 Future research is needed to show a causal relationship between these mutations and the

610 evolution of resistance to amitraz, but these tests must account for the behavioural changes

611 induced by amitraz. Moreover, data from functional analysis via electrophysiology and other

612 approaches will help to fully characterise the interaction of amitraz with wild-type and mutant

613 receptors.

614 The current status in the management of $V$. destructor shows i) a widespread resistance to 615 pyrethroids (Kim et al. 2009; Bak et al. 2012; González-Cabrera et al. 2016; Kamler et al. 2016;

616 González-Cabrera et al. 2018; Millán-Leiva et al. 2021a); ii) increasing cases of failures after 617 treatments with coumaphos (Elzen and Westervelt 2002; Maggi et al. 2009; Maggi et al. 2011);

618 iii) and the overreliance of beekeepers on amitraz (Haber et al. 2019), which may favour the 619 evolution of resistance to this acaricide. In this scenario, monitoring the resistance to acaricidal 620 compounds is crucial to decide whether a given treatment is likely to be successful, as well as to 621 avoid selection pressures with treatments that can lead to an increase of mites carrying 622 mutations conferring resistance. To help on this endeavour, we have developed high throughput 623 allelic discrimination assays based on TaqMan ${ }^{\circledR}$ for detecting $\mathrm{N} 87 \mathrm{~S}$ and $\mathrm{Y} 215 \mathrm{H}$ mutations in the 624 Vd_Oct $\beta_{2} R$, as was previously implemented to detect mutations in the $V$. destructor VGSC associated with resistance to pyrethroids (González-Cabrera et al. 2013; González-Cabrera et al.

626 2016). This assay is relatively cheap, fast, robust and capable of accurately genotype individual 627 mites in poor quality samples. Therefore, the implementation of allelic discrimination assays 628 like those described in this study will be especially suited towards determining the distribution 629 and frequency of mutations associated to resistances in local Varroa populations. This 630 information would be very valuable for designing a more rational control of Varroa, selecting 631 each time the best acaricide for their apiaries. 
634

635

636

637

638

639

640

641

642

643

644

645

646

647

648

649

650

651

652

653

654

655

656

657

658

659

660

661

662

663

664

665

666

667

668

669

670

671

672

673

674

675

Adzhubei IA et al. (2010) A method and server for predicting damaging missense mutations. Nat Methods 7:248-249. doi:10.1038/nmeth0410-248

Afonina I, Zivarts M, Kutyavin I, Lukhtanov E, Gamper H, Meyer R (1997) Efficient priming of PCR with short oligonucleotides conjugated to a minor groove binder. Nucleic Acids Res 25:2657 - 2660

Almecija G, Poirot B, Cochard P, Suppo C (2020) Inventory of Varroa destructor susceptibility to amitraz and tau-fluvalinate in France. Exp Appl Acarol. doi:10.1007/s10493-02000535-w

Aronstein KA, Saldivar E, Vega R, Westmiller S, Douglas AE (2012) How Varroa parasitism affects the immunological and nutritional status of the honey bee, Apis mellifera. Insects 3:601-615. doi:10.3390/insects3030601

Bak B, Wilde J, Siuda M (2012) Characteristics of north-eastern population of Varroa destructor resistant to synthetic pyrethroids. Med Weter 68:603-606

Baron S, van der Merwe NA, Madder M, Maritz-Olivier C (2015) SNP analysis infers that recombination is involved in the evolution of amitraz resistance in Rhipicephalus microplus. Plos One 10:e0131341. doi:10.1371/journal.pone.0131341

Baxter GD, Barker SC (1999) Isolation of a cDNA for an octopamine-like, G-protein coupled receptor from the cattle tick, Boophilus microplus. Insect Biochem Mol Biol 29:461467. doi:10.1016/S0965-1748(99)00023-5

Beaurepaire AL, Truong TA, Fajardo AC, Dinh TQ, Cervancia C, Moritz RF (2015) Host specificity in the honeybee parasitic mite, Varroa spp. in Apis mellifera and Apis cerana. Plos One 10:e0135103. doi:10.1371/journal.pone.0135103

Boecking O, Genersch E (2008) Varroosis - the ongoing crisis in bee keeping. Journal Fur Verbraucherschutz Und Lebensmittelsicherheit-Journal of Consumer Protection and Food Safety 3:221-228. doi:10.1007/s00003-008-0331-y

Bonzini S, Tremolada P, Bernardinelli I, Colombo M, Vighi M (2011) Predicting pesticide fate in the hive (part 1): experimentally determined $\tau$-fluvalinate residues in bees, honey and wax. Apidologie 42:378-390

Braza MKE, Gazmen JDN, Yu ET, Nellas RB (2019) Ligand-induced conformational dynamics of a tyramine receptor from Sitophilus oryzae. Scientific reports 9:16275. doi:10.1038/s41598-019-52478-x

Calatayud-Vernich P, Calatayud F, Simó E, Picó Y (2018) Pesticide residues in honey bees, pollen and beeswax: Assessing beehive exposure. Environmental Pollution 241:106114. doi:10.1016/j.envpol.2018.05.062

Chen AC, He H, Davey RB (2007) Mutations in a putative octopamine receptor gene in amitraz-resistant cattle ticks. Veterinary Parasitology 148:379-383

Corley SW, Jonsson NN, Piper EK, Cutulle C, Stear MJ, Seddon JM (2013) Mutation in the RmbetaAOR gene is associated with amitraz resistance in the cattle tick Rhipicephalus microplus. Proc Natl Acad Sci U S A 110:16772-16777. doi:10.1073/pnas.1309072110

Desneux N, Decourtye A, Delpuech JM (2007) The sublethal effects of pesticides on beneficial arthropods. Annual Review of Entomology 52:81-106. doi:10.1146/annurev.ento.52.110405.091440 
676

677

678

679

680

681

682

683

684

685

686

687

688

689

690

691

692

693

694

695

696

697

698

699

700

701

702

703

704

705

706

707

708

709

710

711

712

713

714

715

Dietemann V et al. (2013) Standard methods for varroa research. In: Dietemann V, Ellis JD, Neumann P (eds) The COLOSS BEEBOOK, Volume II: standard methods for Apis mellifera pest and pathogen research. Journal of Apicultural Research 52(1): http://dx.doi.org/10.3896/IBRA.1.52.1.09, vol 52. vol 1. doi:10.3896/IBRA.1.52.1.09

Eisenberg D, Schwarz E, Komaromy M, Wall R (1984) Analysis of membrane and surface protein sequences with the hydrophobic moment plot. J Mol Biol 179:125-142. doi:10.1016/0022-2836(84)90309-7

Elzen PJ, Baxter JR, Spivak M, Wilson WT (1999) Amitraz resistance in varroa: New discovery in North America. Am Bee J 139:362-362

Elzen PJ, Baxter JR, Spivak M, Wilson WT (2000) Control of Varroa jacobsoni Oud. resistant to fluvalinate and amitraz using coumaphos. Apidologie 31:437-441. doi:10.1051/apido:2000134

Elzen PJ, Eischen FA, Baxter JB, Pettis J, Elzen GW, Wilson WT (1998) Fluvalinate resistance in Varroa jacobsoni from several geographic locations. Am Bee J 138:674-676

Elzen PJ, Westervelt D (2002) Detection of coumaphos resistance in Varroa destructor in Florida. Am Bee J 142:291-292

EMA (2010) Guideline on veterinary medicinal products controlling Varroa destructor parasitosis in bees. https://www.ema.europa.eu/en/documents/scientificguideline/guideline-veterinary-medicinal-products-controlling-varroa-destructorparasitosis-bees_en.pdf. Accessed 16 July 20212021

Farooqui T (2007) Octopamine-mediated neuromodulation of insect senses. Neurochem Res 32:1511-1529. doi:10.1007/s11064-007-9344-7

Farooqui T (2012) Review of octopamine in insect nervous systems. Open Access Insect Physiology. doi:10.2147/oaip.S20911

Feyereisen R, Dermauw W, Van Leeuwen T (2015) Genotype to phenotype, the molecular and physiological dimensions of resistance in arthropods. Pestic Biochem Physiol 121:6177. doi:10.1016/j.pestbp.2015.01.004

Filipek S (2019) Molecular switches in GPCRs. Curr Opin Struct Biol 55:114-120. doi:10.1016/j.sbi.2019.03.017

Finetti L, Roeder T, Calo G, Bernacchia G (2021) The Insect Type 1 Tyramine Receptors: From Structure to Behavior. Insects 12. doi:10.3390/insects 12040315

González-Cabrera $\mathbf{J}$ et al. (2018) A single mutation is driving resistance to pyrethroids in European populations of the parasitic mite, Varroa destructor. Journal of Pest Science 91:1137-1144. doi:10.1007/s10340-018-0968-y

González-Cabrera J, Davies TGE, Field LM, Kennedy PJ, Williamson MS (2013) An amino acid substitution (L925V) associated with resistance to pyrethroids in Varroa destructor. Plos One 8:e82941. doi:10.1371/journal.pone.0082941

González-Cabrera J et al. (2016) Novel Mutations in the voltage-gated sodium channel of pyrethroid-resistant Varroa destructor populations from the Southeastern USA. Plos One 11:e0155332. doi:10.1371/journal.pone.0155332 
Gracia-Salinas MJ, Ferrer-Dufol M, Latorre-Castro E, Monero-Manera C, Castillo-Hernández JA, Lucientes-Curd J, Peribanez-López MA (2006) Detection of fluvalinate resistance in Varroa destructor in Spanish apiaries. J Apicult Res 45:101-105

Haber AI, Steinhauer NA, vanEngelsdorp D (2019) Use of chemical and nonchemical methods for the control of Varroa destructor (Acari: Varroidae) and associated winter colony losses in U.S. beekeeping operations. J Econ Entomol 112:1509-1525. doi:10.1093/jee/toz088

Harrison IR, Kozlik A, McCarthy JF, Palmer BH, Wakerley SB, Watkins TI, Weighton DM (1972) 1,5-di-(2,4-dimethylphenyl)-3-methyl-1,3,5-triazapenta-1,4-diene, a new acaricide active against strains of mites resistant to organophosphorus and bridged diphenyl compounds. Pesticide Science 3:679-680. doi:10.1002/ps.2780030603

Hecht M, Bromberg Y, Rost B (2015) Better prediction of functional effects for sequence variants. BMC Genomics 16:S1. doi:10.1186/1471-2164-16-S8-S1

Hollingworth RM, Lund AE (1982) Biological and neurotoxic effects of amidine pesticides. In: Coats JR (ed) Insecticide Mode of Action. Academic Press, New York, pp 198-227

Hubert J, Nesvorna M, Kamler M, Kopecky J, Tyl J, Titera D, Stara J (2014) Point mutations in the sodium channel gene conferring tau-fluvalinate resistance in Varroa destructor. Pest Manag Sci 70:889-894. doi:10.1002/ps.3679

Janezic EM et al. (2020) N-glycosylation of alpha1D-adrenergic receptor N-terminal domain is required for correct trafficking, function, and biogenesis. Scientific reports 10:7209. doi:10.1038/s41598-020-64102-4

Jonsson NN, Klafke G, Corley SW, Tidwell J, Berry CM, Koh-Tan HC (2018) Molecular biology of amitraz resistance in cattle ticks of the genus Rhipicephalus. Front Biosci (Landmark Ed) 23:796-810. doi:10.2741/4617

Kall L, Krogh A, Sonnhammer EL (2004) A combined transmembrane topology and signal peptide prediction method. J Mol Biol 338:1027-1036. doi:10.1016/j.jmb.2004.03.016

Kamler M, Nesvorna M, Stara J, Erban T, Hubert J (2016) Comparison of tau-fluvalinate, acrinathrin, and amitraz effects on susceptible and resistant populations of Varroa destructor in a vial test. Exp Appl Acarol 69:1-9. doi:10.1007/s10493-016-0023-8

Kearse M et al. (2012) Geneious Basic: an integrated and extendable desktop software platform for the organization and analysis of sequence data. Bioinformatics 28:1647-1649. doi:10.1093/bioinformatics/bts199

Kim W et al. (2009) A geographical polymorphism in a Voltage-Gated Sodium Channel gene in the mite, Varroa destructor, from Korea. Korean Journal of Apiculture 24:159-165

Kita T et al. (2017) Amitraz and its metabolite differentially activate alpha- and beta-adrenergiclike octopamine receptors. Pest Manag Sci 73:984-990. doi:10.1002/ps.4412

Koh-Tan HH, Strachan E, Cooper K, Bell-Sakyi L, Jonsson NN (2016) Identification of a novel beta-adrenergic octopamine receptor-like gene (betaAOR-like) and increased ATPbinding cassette $\mathrm{B} 10$ (ABCB10) expression in a Rhipicephalus microplus cell line derived from acaricide-resistant ticks. Parasit Vectors 9:425. doi:10.1186/s13071-016$1708-\mathrm{x}$ 
Kulhanek K, Garavito A, vanEngelsdorp D (2021) Accelerated Varroa destructor population growth in honey bee (Apis mellifera) colonies is associated with visitation from nonnatal bees. Scientific reports 11:7092. doi:10.1038/s41598-021-86558-8

Kumar R (2019) Molecular markers and their application in the monitoring of acaricide resistance in Rhipicephalus microplus. Exp Appl Acarol 78:149-172. doi:10.1007/s10493-019-00394-0

Li X, Zhou M, Huang W, Yang H (2017) N-glycosylation of the beta2 adrenergic receptor regulates receptor function by modulating dimerization. FEBS J 284:2004-2018. doi:10.1111/febs.14098

Liu N, Li T, Wang Y, Liu S (2021) G-Protein Coupled Receptors (GPCRs) in Insects-A Potential Target for New Insecticide Development. Molecules 26. doi:10.3390/molecules26102993

$\mathrm{Lu} \mathrm{HM}$ et al. (2017) Ligand-binding characterization of simulated beta-adrenergic-like octopamine receptor in Schistocerca gregaria via progressive structure simulation. Journal of molecular graphics \& modelling 77:25-32. doi:10.1016/j.jmgm.2017.07.025

Maggi MD, Ruffinengo SR, Damiani N, Sardella NH, Eguaras MJ (2009) First detection of Varroa destructor resistance to coumaphos in Argentina. Experimental and Applied Acarology 47:317-320. doi:DOI 10.1007/s10493-008-9216-0

Maggi MD, Ruffinengo SR, Mendoza Y, Ojeda P, Ramallo G, Floris I, Eguaras MJ (2011) Susceptibility of Varroa destructor (Acari: Varroidae) to synthetic acaricides in Uruguay: Varroa mites' potential to develop acaricide resistance. Parasitol Res 108:815821. doi:DOI 10.1007/s00436-010-2122-5

Maggi MD, Ruffinengo SR, Negri P, Eguaras MJ (2010) Resistance phenomena to amitraz from populations of the ectoparasitic mite Varroa destructor of Argentina. Parasitol Res 107:1189-1192. doi:10.1007/s00436-010-1986-8

Marsh L (2015) Strong ligand-protein interactions derived from diffuse ligand interactions with loose binding sites. Biomed Res Int 2015:746980. doi:10.1155/2015/746980

Martin S, Hogarth A, Van Breda J, Perrett J (1998) A scientific note on Varroa jacobsoni Oudemans and the collapse of Apis mellifera L. colonies in the United Kingdom. Apidologie 29:369-370

Medici SK, Maggi MD, Sarlo EG, Ruffinengo S, Marioli JM, Eguaras MJ (2016) The presence of synthetic acaricides in beeswax and its influence on the development of resistance in Varroa destructor. J Apicult Res 54:267-274. doi:10.1080/00218839.2016.1145407

Milani N (1995) The resistance of Varroa-Jacobsoni Oud to pyrethroids - a laboratory assay. Apidologie 26:415-429

Milani N, Della Vedova G (2002) Decline in the proportion of mites resistant to fluvalinate in a population of Varroa destructor not treated with pyrethroids. Apidologie 33:417-422. doi:10.1051/apido:2002028

Millán-Leiva A, Marín O, Christmon K, vanEngelsdorp D, González-Cabrera J (2021a) Mutations associated with pyrethroid resistance in Varroa mite, a parasite of honey bees, are widespread across the United States. Pest Manag Sci 77:3241-3249. doi:10.1002/ps.6366 
799

800

801

802

803

804

805

806

807

808

809

810

811

812

813

814

815

816

817

818

819

820

821

822

823

824

825

826

827

828

829

830

831

832

833

834

835

836

837

838

839

840

Millán-Leiva A et al. (2021b) Mutations associated with pyrethroid resistance in the honey bee parasite Varroa destructor evolved as a series of parallel and sequential events. Journal of Pest Science. doi:10.1007/s10340-020-01321-8

Mitton GA et al. (2018) Varroa destructor: when reversion to coumaphos resistance does not happen. J Apicult Res 57:536-540. doi:10.1080/00218839.2018.1475038

Mozes-Koch R, Slabezki Y, Efrat H, Kalev H, Kamer Y, Yakobson BA, Dag A (2000) First detection in Israel of fluvalinate resistance in the varroa mite using bioassay and biochemical methods. Experimental and Applied Acarology 24:35-43. doi:Doi 10.1023/A:1006379114942

Nørskov-Lauritsen L, Bräuner-Osborne H (2015) Role of post-translational modifications on structure, function and pharmacology of class C G protein-coupled receptors. Eur $\mathrm{J}$ Pharmacol 763:233-240. doi:https://doi.org/10.1016/j.ejphar.2015.05.015

Omasits U, Ahrens CH, Muller S, Wollscheid B (2014) Protter: interactive protein feature visualization and integration with experimental proteomic data. Bioinformatics 30:884886. doi:10.1093/bioinformatics/btt607

Page SW (2008) Antiparasitic drugs. In: Maddison JE, Page SW, Church DB (eds) Small Animal Clinical Pharmacology (Second Edition). W.B. Saunders, Edinburgh, pp 198260. doi:https://doi.org/10.1016/B978-070202858-8.50012-9

Patwardhan A, Cheng N, Trejo J (2021) Post-Translational Modifications of G Protein-Coupled Receptors Control Cellular Signaling Dynamics in Space and Time. Pharmacological Reviews 73:120-151. doi:10.1124/pharmrev.120.000082

Rader AJ, Anderson G, Isin B, Khorana HG, Bahar I, Klein-Seetharaman J (2004) Identification of core amino acids stabilizing rhodopsin. Proc Natl Acad Sci U S A 101:7246-7251. doi:10.1073/pnas.0401429101

Ramsey SD et al. (2019) Varroa destructor feeds primarily on honey bee fat body tissue and not hemolymph. Proc Natl Acad Sci U S A 116:1792-1801. doi:10.1073/pnas.1818371116

Rinkevich FD (2020) Detection of amitraz resistance and reduced treatment efficacy in the Varroa Mite, Varroa destructor, within commercial beekeeping operations. Plos One 15:e0227264. doi:10.1371/journal.pone.0227264

Rodríguez-Dehaibes SR, Otero-Colina G, Sedas VP, Jiménez JAV (2005) Resistance to amitraz and flumethrin in Varroa destructor populations from Veracruz, Mexico. J Apicult Res 44:124-125. doi:10.1080/00218839.2005.11101162

Roeder T (2005) Tyramine and octopamine: ruling behavior and metabolism. Annu Rev Entomol 50:447-477. doi:10.1146/annurev.ento.50.071803.130404

Rosenkranz P, Aumeier P, Ziegelmann B (2010) Biology and control of Varroa destructor. J Invertebr Pathol 103:S96-S119. doi:10.1016/j.jip.2009.07.016

Sammataro D, Untalan P, Guerrero F, Finley J (2005) The resistance of varroa mites (Acari : Varroidae) to acaricides and the presence of esterase. Int J Acarol 31:67-74

Solignac M et al. (2005) The invasive Korea and Japan types of Varroa destructor, ectoparasitic mites of the Western honeybee (Apis mellifera), are two partly isolated clones. Proceedings of the Royal Society B-Biological Sciences 272:411-419. doi:DOI 10.1098/rspb.2004.2853 
841 Steinhauer N, Kulhanek K, Antunez K, Human H, Chantawannakul P, Chauzat MP, vanEngelsdorp D (2018) Drivers of colony losses. Curr Opin Insect Sci 26:142-148. doi:10.1016/j.cois.2018.02.004

844 Techer MA et al. (2019) Divergent evolutionary trajectories following speciation in two ectoparasitic honey bee mites. Commun Biol 2:357. doi:10.1038/s42003-019-0606-0

846 Traynor KS et al. (2020) Varroa destructor: A Complex Parasite, Crippling Honey Bees Worldwide. Trends Parasitol 36:592-606. doi:10.1016/j.pt.2020.04.004

Venselaar H, te Beek TAH, Kuipers RKP, Hekkelman ML, Vriend G (2010) Protein structure analysis of mutations causing inheritable diseases. An e-Science approach with life scientist friendly interfaces. BMC Bioinformatics 11:548. doi:10.1186/1471-2105-11548

Vlogiannitis S et al. (2021) Reduced proinsecticide activation by cytochrome P450 confers coumaphos resistance in the major bee parasite Varroa destructor. Proc Natl Acad Sci U S A 118. doi:10.1073/pnas.2020380118

855

Yang J, Zhang Y (2015) I-TASSER server: new development for protein structure and function predictions. Nucleic Acids Res 43:W174-181. doi:10.1093/nar/gkv342

Zhang D, Zhao Q, Wu B (2015) Structural studies of G protein-coupled receptors. Mol Cells 38:836-842. doi:10.14348/molcells.2015.0263 


\section{TABLES}

Table 1. Frequency of the N87S mutation in the samples collected from several French departments.

\begin{tabular}{|c|c|c|c|c|c|}
\hline Colony & Department & $\mathbf{n}$ & Last treatment & Collection & $\%$ N87S mutation \\
\hline DTRA & Isère (38) & 24 & Amitraz & POST-Treatment & $100 \%$ \\
\hline MAP & Loire (42) & 24 & Amitraz & POST-Treatment & $75 \%$ \\
\hline MHRA & Isère (38) & 24 & Amitraz & POST-Treatment & $71 \%$ \\
\hline $\mathrm{J} 11$ & Puy-de-Dôme (63) & 23 & Amitraz & POST-Treatment & $74 \%$ \\
\hline MM16 & Puy-de-Dôme (63) & 24 & Amitraz & POST-Treatment & $58 \%$ \\
\hline VBA & Alpes-de-Haute-Provence (04) & 20 & Oxalic acid & PRE-Treatment & $0 \%$ \\
\hline $\mathrm{AmA}$ & Maine-et-Loire (49) & 24 & Oxalic acid & PRE-Treatment & $0 \%$ \\
\hline $\mathrm{DE}$ & Drôme (26) & 19 & Oxalic acid & PRE-Treatment & $26 \%$ \\
\hline
\end{tabular}




\section{FIGURE LEGENDS}

Figure 1. Phylogenetic tree of octopamine receptors across several species of arthropods. Neighbor-Joining tree was constructed in Geneious 9.1.8. Oct $\alpha_{2} R$ : $\alpha_{2}$-adrenergic-like octopamine receptor; $\operatorname{Oct} \beta_{1} \mathrm{R}$ : octopamine $\beta_{1}$ receptor; Oct $\beta_{2} \mathrm{R}$ : octopamine $\beta_{2}$ receptor; Oct $\beta_{3} \mathrm{R}$ : octopamine $\beta_{3}$ receptor; TAR1: type 1 tyramine receptor. Ac: Acyrthosiphon pisum; Ae: Aethina tumida; Am: Apis dorsata; Am; Apis mellifera; Bi: Bombus impatiens; Bm: Bombyx mori; Cs: Centruroides sculpturatus; Dv: Diabrotica virgifera virgifera; Dm: Drosophila melanogaster; Go: Galendromus occidentalis; Ha: Helicoverpa armigera; Is: Ixodes scapularis; Lp: Limulus polyphemus; Ms: Manduca sexta; Mr: Megachile rotundata; Nv: Nicrophorus vespilloides; Of: Ostrinia furnacalis; Pa: Periplaneta americana; Rm: Rhipicephalus microplus; Tc: Tribollium castaneum; Tm: Tropilaelaps mercedesae; Vd: Varroa destructor. The GenBank accession numbers of the receptor sequences in the tree are listed in Table S2.

Figure 2. Multiple sequence alignment of Oct $\alpha$ Rs (A), Oct $\beta R s(B)$, and TAR1 (C) from diverse acari species. The shaded sequences highlight the amino acid identity level. The seven $\alpha$-helices are represented as grey rectangles and numbered as H I-VII. GPCR conserved motifs in helix III (D[E]RY), helix VI (CWxP), helix VII (NP[L/I]IY), and C-terminus $(\mathrm{F}[\mathrm{R} / \mathrm{K}] \mathrm{xx}[\mathrm{F} / \mathrm{L}] \mathrm{xxx})$ are indicated by bars. Vd: Varroa destructor; Tm: Tropilaelaps mercedesae; Go: Galendromus occidentalis; Is: Ixodes scapularis; Rm: Rhipicephalus microplus.

Figure 3. Three-dimensional structure of $\operatorname{Vd} \_\operatorname{Oct} \beta_{2} R$ (A) and $V d \_T A R 1$ (B), obtained by modelling with I-TASSER (Yang and Zhang 2015). The receptors are showed as ribbon representation in rainbow colouring ( $\mathrm{N}$-terminus, blue; $\mathrm{C}$-terminus, red). The seven $\alpha$-helices are connected by three extracellular loops (EL1-3) and three intracellular loops (IL1-3). 
Figure 4. Snake plot of Vd_Oct $\beta_{2} \mathrm{R}$ with transmembrane domains predicted with Phobius (Kall et al. 2004). N87S mutation (magenta); Y215 mutation (red); putative N-glycosylation residues (diamond); GPCR conserved motifs (yellow); putative disulphide bond residues (blue); predicted ligand binding residues (orange).

Figure 5. Schematic diagram of $\operatorname{oct}_{2} r(\mathrm{~A}), \operatorname{oct} \beta_{2} r(\mathrm{~B})$, and tarl (C) exon-intron gene structure. Coding sequence (CDS) are shown in black. Lengths are represented in bp.

Figure 6. Electropherograms showing the mutations in the sequence of $\mathrm{Vd}$ _Oct $\beta_{2} \mathrm{R}$. The substitution of A by $G$ at position 260 of the ORF results in the N87S mutation (A), whereas the substitution of $\mathrm{T}$ by $\mathrm{C}$ at position 643 results in the $\mathrm{Y} 215 \mathrm{H}$ mutation (B).

Figure 7. Timeline of the $\mathrm{Y} 215 \mathrm{H}$ mutation incidence in colonies from U.S. The name of the colonies in the Y axe shows the state and the year of sample collection. DE: Delaware; MA: Massachusetts; MI: Michigan; MT: Montana; NJ: New Jersey; OR: Oregon; PA: Pennsylvania. More detailed information can be found in Table S1.

Figure 8. Real-time $\operatorname{TaqMan}^{\circledR}$ detection of the N87S (A) and $\mathrm{Y} 215 \mathrm{H}$ (B) mutations in Vd_Oct $\beta_{2} R$. In the scatter plots of $\mathrm{VIC}^{\circledR}$ and $6 \mathrm{FAM}^{\mathrm{TM}}$ fluorescence, each dot represents an individual mite. SS homozygotes (N87 or Y215 allele) in red; RS heterozygotes in green; RR homozygotes ( $\mathrm{S} 87$ or $\mathrm{H} 215$ allele) in blue. 
Oct $\alpha_{2}-\mathrm{R}$

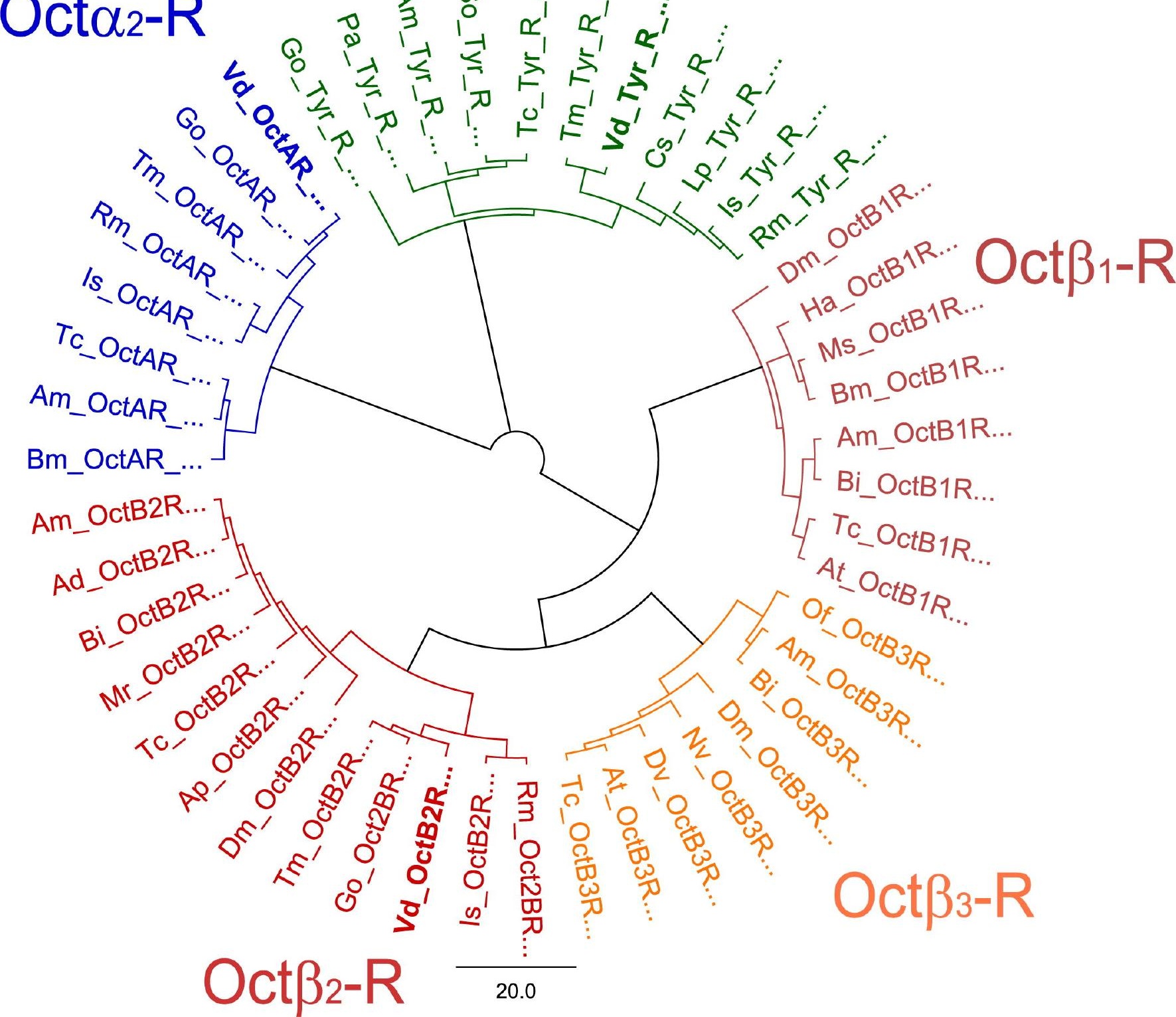



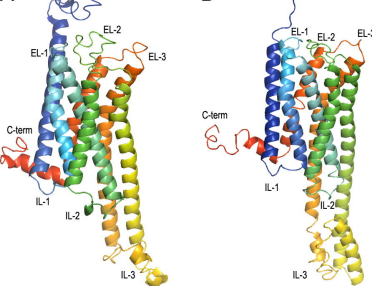
$\mathrm{H}_{2} \mathrm{~N}-\mathrm{M}$

(1)

extra TM1

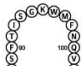

(ㄷ) $1 \mathrm{DOP}$

(C) (c)

(R)

(H)

(E)

(5)

(c)

(c) (c)

TM2\& TM3

(v) (5)

(v) (K) (A)

(s)

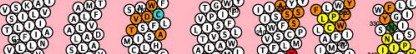

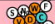

तबल

TMG

$\mathrm{TM}_{3 \mathrm{~m}} 8$

8 (v) SO SDOV

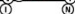

(B)

(N)

(H)

(T)

a
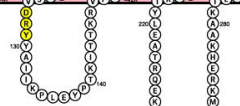

W $(\bar{Y}) \mathrm{Y}$

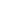



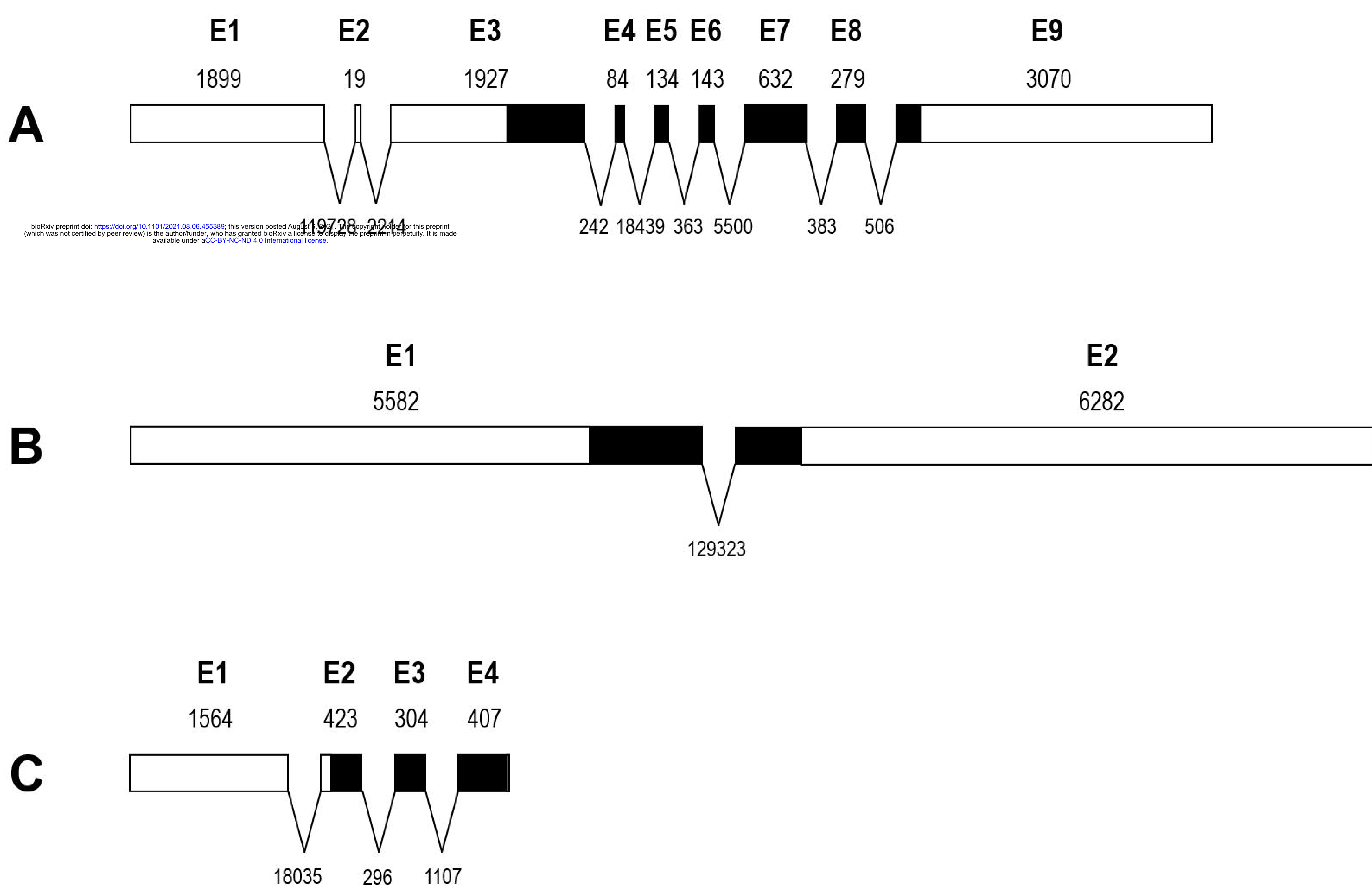
260

\begin{tabular}{lllllllllllll} 
IC & $A$ & $T$ & $T$ & $C$ & $A$ & $A$ & $T$ & $G$ & $C$ & $G$ & $T$ & $C$ \\
\hline$T$ & & & $F$ & & & $N$ & & & $A$ & & & \\
\hline
\end{tabular}

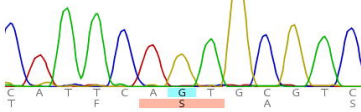

643

\begin{tabular}{lllllllllllll}
\hline & $C$ & $A$ & $C$ & $T$ & $T$ & $A$ & $T$ & $T$ & $G$ & $G$ & $C$ & $G$ \\
$F$ & & & $T$ & & & $Y$ & & & $\mathbb{W}$ & & & \\
\hline
\end{tabular}

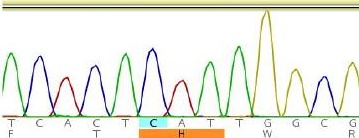


PA-07. 2016

bioRxiv preprint dol: https://doi.org/10.1101/2021.08.06.455389; this version posted August 6, 2021. The copyright holder for this preprint (which was npt certifieg by peer review) is the author/funder, who has granted bioRxiv a license to display the preprint in perpetuity. It is made
available under aCC-BY-NC-ND 4.0 International license.

PA-11_2020-

OR-24_2017

OR-1685_2017

OR-1681_2017-

OR-AL51_2018-

OR-AL38_2018-

NJ-11_2016-

NJ-08_2016-

NJ-03_2016-

NJ-M-001_2018-

NJ-EP-2_2018-

NJ-M-002_2018-

NJ-M-008_2018-

MT-03_2017-

MT-20_2017-

MT-13_2020-

MI-09_2016-

MI-04_2016-

MI-19_2017-

MI-58_2018-

MI-56_2018-

MA-21_2016-

MA-22_2016-

MA-13_2017-

MA-10_2020-

DE-19_2016-

DE-13_2016-

DE-22_2020

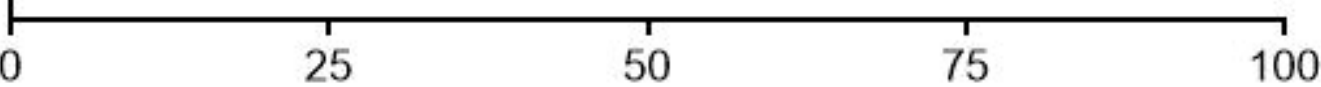




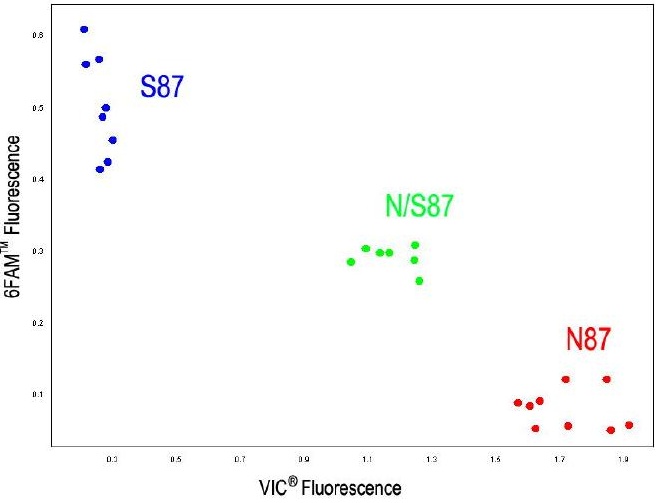

$B$

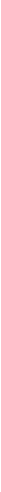

